\title{
Sex, abortion and Obama
}

\section{Rosalind Joseph}

Foundation Year 1 Doctor

Correspondence to

Rosalind Joseph;

rosalind.joseph@btuh.nhs.uk

Received 20 April 2011

Accepted 15 September 2011

Published Online First

15 November 2011

\section{Background}

The immortal words "Yes, We Can" will forever be ingrained in the memory of anyone following the United States (US) presidency campaign stretching from early 2007 to late 2008. When President Barack Obama was inaugurated into office, the whole world knew it was a historic moment. He had easily defeated Republican rival John McCain to become the first black President of the USA. Moreover, the world was now ready for change. And Obama convinced the US people that he could deliver, with those words: "Yes, We Can". However, after completing his first year in office in 2009, the optimism had drained away and critics have been questioning whether Obama's well-crafted speeches and charisma have any true substance. Domestically, his presidency has been dominated by his controversial attempts to reform the US health care system. Internationally, his policies towards Afghanistan, nuclear disarmament, the debt crisis and climate change have been high priorities, but open to harsh criticism and limited success. While Obama has been criticised from his first year in office, some of his true successes have been overshadowed, namely his desire to place reproductive and sexual health at the heart of his presidency.

The World Health Organization (WHO) defines sexual health as "a state of physical, emotional, mental and social well-being related to sexuality; not merely the absence of disease, dysfunction or infirmity. Sexual health requires a positive and respectful approach to sexuality and sexual relationships, as well as the possibility of having pleasurable and safe sexual experiences, free of coercion, discrimination and violence". ${ }^{1}$ This definition ties closely with two key areas: access to comprehensive and accessible family planning services and sex education; two issues that have been highly contentious and politicised within the USA. Induced abortion particularly has been heavily rooted in US political struggles, attracting mass media attention during the presidency campaigns. This essay will analyse the USA's impact on sexual health care, both domestically and internationally. We will explore how President Obama has propelled the USA back into the international reproductive health arena, particularly focusing on the USA's impact on unsafe abortion globally. The USA's attitude towards sex education and health care will also be examined.

Approximately one in five pregnancies worldwide end in abortion. However, $55 \%$ of abortions in developing countries are performed in unsafe surroundings by unskilled providers. Unsafe abortion is defined as a "procedure for terminating an unintended pregnancy carried out either by persons lacking the necessary skills or in an environment that does not conform to minimal medical standards, or both". ${ }^{2}$ It was estimated that in 2003 approximately 42 million pregnancies were voluntarily terminated: 22 million safely and 20 million unsafely ... 47000 maternal deaths are estimated to have been due to unsafe abortion ... remaining close to $13 \%$ of all maternal deaths. ${ }^{3}$ Important steps to tackle the issue and reverse these shocking statistics have been put in place, namely the Millennium Development Goals (MDGs), which promote a global effort to tackle global problems such as maternal mortality (MDG 5). However, it is unlikely that this will be achieved unless unsafe abortion, the fifth leading cause of maternal mortality, is addressed. The USA is an important actor in reproductive health, providing much needed funding in the developing world. Within the USA, abortion politics has been widely publicised due to powerful and radical activists grabbing the media spotlight. However, US foreign policy concerning abortion has largely been overlooked. During the time of George W Bush's 8 years in presidency from 2001 to 2009, the USA's role was condemned due to the highly controversial foreign aid assistance programme the Mexico City Policy. 


\section{Mexico City Policy}

The Mexico City Policy, also known as the 'Global Gag Rule', was announced by President Reagan in 1984. The Policy required that in exchange for US family planning assistance and funding, non-US nongovernmental organisations must have certified that they will not use even their own, privately raised funds to provide or even inform women of safe abortion services or advocate a reform of restrictive abortion laws. ${ }^{4}$ It essentially barred recipients of US foreign assistance from promoting abortion for fertility control. It is worth remembering that abortion is legal in the USA, and enacting a similar policy within the USA would have been against US constitutional rights. Since constitutional rights protected liberal abortion laws in the USA, focus in the 1980s shifted to preventing abortions taking place abroad. Reagan responded to his powerful anti-abortion, fundamentalist Christian constituency by enacting the Mexico City Policy.

The primary aim of the Mexico City Policy was to decrease the incidence of abortion abroad. Globally, there has been a moderate decline in the number of abortions, from 45.6 million in 1995 to 41.6 million in 2003, a 9\% decline. ${ }^{5}$ Although abortion-related maternal mortality has also decreased, the proportion of unsafe abortion has increased from $44 \%$ to $48 \%$ between 1995 and 2003, ${ }^{6}$ particularly in developing countries. Furthermore, the difficulty in data-gathering due to religious and cultural issues means that these figures are likely to be underestimated. From the data there seems to be no conclusive evidence that the Mexico City Policy was successful in reducing abortion. This is apparent when we acknowledge that the most dramatic decline in abortion (a 42\% decline) occurred in Europe, where legal and safe abortion services are readily accessible, contraceptive advice is acceptable and sex education in encouraged.

By opposing liberalisation of strict abortion laws, the Policy also encouraged societies to stigmatise women who seek abortions, driving abortion underground. According to some, the most important single determinant of abortion's impact on women's health is its legal status. ${ }^{7}$ Anti-abortion groups claim that restrictive legislation on abortion and contraception will reduce the incidence of abortion. However, the lowest abortion rates in the world are in Europe, rates being below 10 per 1000 women, whereas in Africa, Latin America and the Caribbean, where abortion is highly restricted, the rates range from the mid-20s to as high as 39 per 1000 women. ${ }^{8}$ In Romania, the shifting of abortion laws showed dramatic differences in abortion-related mortality. In 1966, the newly enshrined Ceausescu regime banned abortion and family planning services. In 1985, the decree was further restricted; imports of contraceptives were also banned. Abortion-related mortality soared; a rise from 80 deaths per 100000 live births in 1964 to 180 deaths per 100000 live births in $1988 .{ }^{9}$ A distressing legacy has also been left; many women who could not obtain an illegal abortion service bore unwanted children. Approximately 150000 to 200000 unwanted children, many severely handicapped, were placed into institutional care for life. ${ }^{10}$ The overwhelming evidence is that in illegal environments unqualified abortionists can act with relative impunity and ignore any minimum standard of care. Despite this evidence, the USA decided to support strict laws and put women's lives at risk, using the Mexico City Policy.

In 2009, President Obama demonstrated that he is strongly committed to women's health and family planning assistance by immediately overturning the Mexico City Policy on his third day of office. Obama stated amidst the controversy: "It is clear that the provisions of the Mexico City Policy are unnecessarily broad and unwarranted ... it is right for us to rescind this policy and restore critical efforts to protect and empower women and promote global economic development ... For too long, international family planning assistance has been used as a political wedge issue, the subject of a back and forth debate that has served only to divide us. It is time that we end the politicisation of this issue". ${ }^{11}$ The WHO commented that "President Obama has sent a powerful signal about the high priority his administration gives to maternal health". ${ }^{12}$ This is particularly important since, for several years, European nations have far outspent the USA in terms of the proportion of gross domestic product allocated to foreign assistance. Some believe that the Bush administration had left Europe to pick up the slack in family planning funding and other aspects of promoting sexual health. It will be some time before the effects of Obama's decision will be seen. However, many international organisations dedicated to family planning and sexual health care are optimistic that the huge funding boost and nod from the USA will have a positive impact on reproductive health and women's rights. The Planned Parenthood Action Centre commented that the "Global Gag Rule was a threat to the health of millions of women.... It's been a long eight years, and we have a lot more work to do to roll back President Bush's awful legacy on women's health". ${ }^{13}$

\section{Abstinence-only education}

The controversial issue of abortion is not the only issue Americans have found difficult to deal with. The USA has had a longstanding complicated relationship with sexual health care and education, once again coming under scrutiny from leading reproductive health organisations. During the Bush era, there was a massive push for abstinence-only education both at home and abroad. The ABC guidance' became increasingly popular (ABC is short for abstain, be faithful and use condoms.) According to some, this focus on abstinence-only programmes has 
severely hampered health education classes, with fewer students understanding topics such as contraception and sexually transmitted infection (STI) prevention. This is potentially lifesaving knowledge and therefore raises some ethical questions. Further to the health problems, it has been commented that abstinence-only education has prevented the American youth from having important conversations about sex and relationships. In comparison, countries such as Sweden, Switzerland and The Netherlands have little societal pressure to remain abstinent, but it is strongly emphasised to teenagers that sexual activity should occur within committed and loving relationships. Therefore, teenagers from these Northern European countries tend to have longer-lasting relationships, fewer sexual partners and lower STI rates even though they actually begin having sex at about the same age as their North American counterparts. ${ }^{14}$ However, as Arai comments, sexual openness and sex education cannot be the only factors in determining teenage sexual activity. ${ }^{15}$ For example, although Northern Europeans have a longstanding proactive delivery of sex education with resultant low levels of teenage pregnancies, Mediterranean countries such as Italy have a different approach. They "leave much more of the sex education to youth themselves". ${ }^{16}$ "Sex education is not mandatory; parents have the right to withdraw children from classes and provision is sparse." 17 However, Italy has low teenage conception and birth rates, even with this haphazard approach to sex education. Clearly, there are multiple factors at play that determine sexual behaviour. But, much of the evidence still points to varied pregnancy and STI/HIV prevention programmes in helping to reduce teenage pregnancy and STI rates. ${ }^{18}$

In addition to the drive for abstinence-only education within the country, the Bush administration pushed their ideals abroad too. The new global AIDS programme PEPFAR (US President's Emergency Plan for AIDS Relief) had a rigid spending requirement that one-third of all HIV prevention funds be reserved for abstinence-only programmes. PEPFAR's sexual prevention strategy was to "delay sexual debut, promote monogamy, fidelity, partner reduction and abstinence". This is in contrast to many reproductive health organisations strongly campaigning that it is only comprehensive sex education that increases contraceptive use and delays sex. However, Bush supporters and advocates of abstinence-only education have long claimed that providing information about contraception and distributing condoms may give a conflicting message to young people. In their eyes, this would present abstinence and condom use as equally viable and would encourage sexual activity. However, recipients of abstinence education were no more likely that non-recipients to delay sexual initiation and had the same number of sexual partners. Worse still, there were some negative impacts on teenagers' willingness to use contraception to prevent pregnancy and STIs. ${ }^{19}$

\section{Virginity pledges}

At the centrepiece of many abstinence education programmes, there has been a new trend in the USA of 'virginity pledges'. The 'Silver Ring Thing' is one particular youth group that promotes sexual abstinence, with young people wearing a silver ring to publicise their abstinence. These 'virginity pledges' have become increasingly popular among adolescents in the USA. Their popularity has shocked many, but the Silver Ring Thing certainly does have quite a fashionable quality, with road shows and concerts appealing to the youth. In an era of globalisation, the USA has long been a trendsetter; with the developing world looking at the USA perhaps as the 'Western ideal', and imitating their actions. This is worrying; potentially an abstinence-only movement may brew in developing countries. But without the access to contraceptives or family planning clinics that USA citizens enjoy, it begs the question: Where will adolescents in developing countries turn to if they fail to be abstinent? The Silver Ring Thing has been transported to the UK but has not had the same welcoming or popularity as in the USA. UK teenagers remain much more sceptical about the seemingly radical group. There has in fact been criticism that these 'virginity pledges' actually have a negative influence. According to research, most adolescents that pledged to remain virgins, broke their vows and "were less likely to use condoms and to seek testing and treatment for STIs than those who never took a virginity pledge". ${ }^{20}$ Furthermore these pledges may prompt some teenagers to engage in other potentially risky sexual behaviours, such as oral or anal sex, in order to technically preserve their virginity. Sex education is a highly contentious issue, with both abstinence programmes and comprehensive education programmes arguing that their methods are the most effective. Despite the arguments, it could be said that both have common goals; goals which Reiss defines as "stopping girls getting pregnant; reducing the incidence of sexually transmitted diseases; decreasing ignorance, guilt, embarrassment and anxiety; enabling young people to make their own decisions about their sexuality; helping young people to develop assertiveness, to question the present role of men and women in society; and providing an ethical framework for the expression of sexuality". ${ }^{21}$ But the achievement of these goals is difficult to measure with variable evidence for both routes.

In contrast to the Bush administration's relentless drive for abstinence despite the evidence, President Obama has redirected $\$ 138$ million from abstinenceonly programmes to "science-based programs to prevent teen pregnancy". 22 Although this has been met by a Republican backlash, it is generally believed that the President has sent a strong message about his desire to 
place reproductive health at the core of his administration, and finally end the politicisation of international family planning assistance.

\section{Concluding remarks}

Although the USA is a pioneer in research, an icon of democracy and a global trendsetter, its major political clout and funding allowance can have both a positive or devastating effect globally. While seen as a country that is always looking ahead at future endeavours, the USA has somewhat been held back by its stubborn views on topics such as sexual health care, rooted in history, politics and religion. Some believe that President Obama is now at last reflecting the changing attitudes in the USA; attitudes that are moving towards more positive positions on many social issues, from abortion to gay marriage. However, with the 2012 Presidential election pending, the future is looking uncertain for Obama. In November 2010, the Democrats lost control of the House and the now Republican-controlled House of Representatives causes worry among leading reproductive health care organisations. Three bills are currently under consideration in Congress that would potentially limit abortion: the Abortion Non-Discrimination Act, No Taxpayer Funding for Abortion Act, and Protect Life Act, ${ }^{23}$ and the world's eyes are currently focused on the debt crisis in the USA. Obama's commitment to comprehensive sex education, family planning services and women's rights has been overshadowed. But many reproductive health campaigners view Obama's stance on women's health and reproductive choice as a key success in a sea of other controversial issues. Although the future is uncertain, Obama has forced the USA to finally accept that it must confront its fear of sexual health care, and in doing so has answered the questions of many reproductive health organisations with "Yes, We Can".

\section{Competing interests None.}

Provenance and peer review Not commissioned; externally peer reviewed.

\section{References}

1 World Health Organization (WHO). Defining Sexual Health: Report of a Technical Consultation on Sexual Health 28-31 January 2002. Geneva, Switzerland: WHO, 2006. http://www. who.int/reproductivehealth/publications/sexual_health/defining sexual_health.pdf [accessed 10 July 2011].

2 World Health Organization (WHO). Unsafe Abortion: Global and Regional Estimates of the Incidence of Unsafe Abortion and Associated Mortality in 2003. Geneva, Switzerland: WHO, 2007.

3 World Health Organization (WHO). Unsafe Abortion; Global and Regional Estimates of the Incidence of Unsafe Abortion and Associated Mortality in 2008. Geneva, Switzerland: WHO, 2011. http://whqlibdoc.who.int/publications/2011/9789241501118_ eng.pdf [accessed 10 July 2011].

4 Cohen S. Abortion politics and the U.S. population aid: coping with a complex new law. Int Fam Plan Perspect 2000;26:137-139.
5 Committee on Foreign Affairs. The Mexico City Policy/Global Gag Rule: Its Impact on Family Planning and Reproductive Health. Washington, DC: Committee on Foreign Affairs, 2007.

6 Sedgh G, Henshaw S, Singh S, et al. Induced abortion: estimated rates and trends worldwide. Lancet 2007;370:1338-1345.

7 Gorrette N, Nabukera S, Salihu HM. The abortion paradox in Uganda: fertility regulator or cause of maternal mortality. J Obstet Gynaecol 2005;25:776-780.

8 Cohen S. New data on abortion incidence, safety incidence key aspects of worldwide abortion debate. Guttmacher Policy Review 2007;10:2-5.

9 World Health Organization (WHO). Abortion and Contraception in Romania: A Strategic Assessment of Policy, Programme and Research Issues. Geneva, Switzerland: WHO, 2007.

10 Stephenson P, Wagner M, Badea M, et al. Commentary: the public health consequences of restricted induced abortion - lessons from Romania. Am J Public Health 1992;82:1328-1331.

11 The White House, Office of the Press Secretary. Statement of President Barack Obama on Rescinding the Mexico City Policy. 2009. http://www.whitehouse.gov/the_press_office/Statemen tofPresidentBarackObamaonRescindingtheMexicoCityPolicy/ [accessed 10 July 2011].

12 The Partnership for Maternal, Newborn and Child Health, World Health Organization. Partnership Welcomes President Obama's Decision to Restore US Funding for Global Family Planning. 2009. http://www.who.int/pmnch/media/press_ materials/pr/2009/20090126_familyplanning/en/ [accessed 10 July 2011].

13 Planned Parenthood of the Rocky Mountains. Dialogue. Winter Issue 2009. http://www.plannedparenthood.org/rockymountains/files/Dialogue_winter09.pdf [accessed 10 July 2011].

14 Dailard C. Legislating against arousal: the growing divide between federal policy and teenage sexual behaviour. Guttmacher Policy Review 2006;9.

15 Arai L. British policy on teenage pregnancy and childbearing: the limitations comparisons with other European countries. Crit Soc Pol 2003;23:89.

16 Teitler J. Trends in youth sexual initiation and fertility in developed countries 1960-1995. Annals AAPSS 2002;580:134-152.

17 Kane R, Wellings K. Reducing the Rate of Teenage Conception: An International Review of the Evidence - Data from Europe. Oxford, UK: Health Education Authority, 1999.

18 Kirby D. Emerging Answers: Research Findings on Programs to Reduce Teenage Pregnancy (Summary). Washington, DC: The National Campaign to Prevent Teen Pregnancy, 2001.

19 Guttmacher Institute Media Centre. Abstinence-Only Programs Do Not Work, New Study Shows, 2007. http:// www.guttmacher.org/media/inthenews/2007/04/18/index.html [accessed 2 November 2011].

20 Rosenbaum JE. Patient teenagers? A comparison of the sexual behavior of virginity pledgers and matched nonpledgers. Paediatrics 2009;123:110-120.

21 Reiss MJ. How should we teach in schools about sexual orientation? A rejoinder to Petrovic. J Moral Educ 1999;28:211-214.

22 Department of Health and Human Services. Fiscal Year 2010 Budget in Brief. 2009. http://www.hhs.gov/asrt/ob/ docbudget/2010budgetinbrief.pdf [accessed 10 July 2011].

23 Devi S. Obama rescinds "overly broad” Bush-era conscience rule. Lancet 2011;377:981. 